\begin{abstract}
Resumo
Visando compreender a construção da degradação com que muitos rios urbanos brasileiros alcançaram o século $X X I$, buscou-se referências que esclarecessem o contexto fluvial urbano na virada do século XIX para o XX. Das obras selecionadas, destacou-se a de Saturnino de Brito pela diversidade de situações abordadas e por seu caráter inovador. Da análise de quatro cidades onde atuou, constatou-se que havia conhecimento cientifico suficiente para ter minimizado os danos aos corpos d'água e que seu trabalho contribuiu para salvaguardar parte desse patrimônio natural para o futuro das cidades.
\end{abstract}

Palavras-chave: águas urbanas, degradação fluvial, Saturnino de Brito.

1 Cumpre esclarecer, antes de prosseguir, que acolhe-se a colocação de Pádua (2004, p. 72), de que os primitivos habitantes do Brasil, apesar de terem registrado sua presença na paisagem, "não chegaram a produzir processos massivos do que hoje classificaríamos como "degradação ambiental": e que entende-se por "degradação" de um rio, o processo decorrente de ações antrópicas que determina a perda total ou parcial das características naturais do corpo d'água; que compromete o desenvolver de suas funções; que implica em alterações na biodiversidade nele contida ou a ele associada, e que repercute no ambiente

... continua próxima página.. busca pela compreensão de como se deu a construção da degradação com que muitos rios urbanos brasileiros alcançaram o século XXI, utilizando os axiomas de Lewis (1979) e procedimentos adotados por Lista \& Sabaté (2010) nas leituras das paisagens que analisam, implicou na necessidade de identificar as motivações e ações que concorreram para tal, a partir do início do século XVI, no âmbito da mata Atlântica - locus do primeiro contato com o solo brasileiro e do início da colonização. ${ }^{1}$

Considerando o caráter sistêmico das bacias hidrográficas, buscou-se inicialmente identificar, de modo geral, no recorte eleito, os impactos mais recorrentes e significativos ao ambiente fluvial e as suas repercussões, para, em seguida, aprofundar a leitura destas no ambiente urbano.

Diante da exuberância da natureza aqui encontrada à época do Descobrimento, a estratégia do colonizador

\section{Marilia de Azevedo Dieb}

Doutora em Urbanismo pela Universidade do Rio de Janeiro PROURB/FAU/UFRJ, com doutorado-sanduíche na ETSAB Escola Tècnica Superior d'Arquitectura de Barcelona, professora doutora do Departamento de Arquitetura e Urbanismo da Universidade Federal da Paraíba, Cidade Universitária, s/n, Castelo Branco, João Pessoa, PB, CEP 58051-900, mariliadieb@hotmail.com foi explorar "a ferro e fogo" os recursos naturais da mata Atlântica, num primeiro momento, e, além dela, posteriormente, baseando-se no extrativismo, na monocultura, na rudimentar produção de açúcar, na pecuária e, somente a partir do final do século XVIII, na incipiente indústria (naval, têxtil, fundições, materiais construtivos básicos, papel, entre outras), cujas matérias-primas, insumos e fontes de energia eram providos pela natureza. Os assentamentos humanos (urbanos e rurais) também se estabeleceram e se desenvolveram a partir do uso indiscriminado de recursos naturais presentes nas florestas, nos manguezais, nas jazidas de pedra e barro, nos rios e nos solos férteis a eles adjacentes (DEAN, 1996).

Foram pontuais as iniciativas da Coroa Portuguesa e dos governos que a sucederam de buscar opiniões ou eficientes gestores, visando otimizar as atividades econômicas e aprimorar a apropriação dos recursos naturais. No entanto, os pareceres, 
... continuação da nota 1 ... circundante, alterando negativamente a paisagem, instaurando riscos à saúde e à segurança das pessoas, conforme definiram Araújo, Almeida \& Guerra (2005, p. 19-20) e Sánchez (2006)

2 Saturnino de Brito atuou em Aracajú (SE); Alegrete, Cachoeira, Cruz Alta, Iraí, Sant'Ana do Livramento, Santa Maria, São Gabriel, São Leopoldo, Passo Fundo Pelotas, Rio Grande, Rosário, Uruguaiana, (RS); Belém (PA); Belo Horizonte, Juiz de Fora, Poços de Caldas, Teófilo Otoni e Uberaba (MG); Campinas, Limeira, Santos e São Paulo (SP); Campos, Itaocara, Rio de Janeiro, Paraíba do Sul e Petrópolis (RJ); Curitiba (PR): João Pessoa (PB); Vitória (ES) e Recife (PE). sugestões e recomendações obtidos raramente foram implementados na totalidade, e levou-se à frente o modelo predatório e imediatista que promoveu o desperdício dos citados recursos e legou ao Brasil do século $X X$, por vezes, um cenário ambiental degradado (DEAN, 1996).

Conforme Ministério do Meio Ambiente (2009), os impactos ambientais decorrentes da ocupação e das atividades humanas implementadas nesses quatro séculos de exploração indiscriminada principal-mente as atividades agrícolas e extrativas - consumiram 92\% da mata Atlântica. Considerando que a qualidade e a vida dos rios estão intrinsecamente conectadas e são garantidas tanto pela estabilidade do solo adjacente como pela presença da vegetação ciliar e da mata como um todo (ARAÚJO, ALMEIDA \& GUERRA, 2005), é correto afirmar que os impactos aos rios localizados na costa oriental brasileira são inegáveis e não têm sido modestos.

Ao final da década de 1880, muitos núcleos urbanos brasileiros se encontravam severamente ameaçados por questões sanitárias, principalmente devido à ausência do poder público em prover serviços de limpeza urbana e de infraestrutura básica e do total despreparo destes núcleos para atender, dentre outras demandas da crescente população urbana, aquela relativa ao provimento de habitações dignas e seguras. Tal condição ambiental não era exclusividade das cidades brasileiras. Ao discorrer sobre a trajetória da higiene humana no pensamento ocidental europeu, Vigarello (1996, p. 254-255) afirma que somente a partir do final do século XIX, o olhar à água passa, timidamente, a incluir a higiene humana e de seus assentamentos. Tal mudança refletiu na concepção dos espaços, inclusive, e principalmente, do urbano:

Os cuidados com o corpo implicam aqui uma reestruturação total do mundo subterrâneo e aéreo das cidades. Foi a água, decerto, um dos fatores mais importantes da reforma urbana no século XIX. Com ela, tanto a alimentação como a 'respiração' dos aglomerados foram alterados. A limpeza, portanto, envolveu o imaginário das cidades, sua tecnologia, sua resistência, também, a serem 'capilarizadas'. (VIGARELLO, 1996, p. 254-255)

Dessa forma, a aquisição da salubridade urbana se viu atrelada, inevitavelmente, às reformas ur- banísticas que incluíram intervenções significativas nas águas existentes nas cidades. A apropriação do modelo europeu na modernização urbana e no enfrentamento das questões sanitárias instaladas não se deu apenas pela crença no seu apuro técnico, mas como estratégia diplomática para estreitar laços políticos e econômicos, atrair investidores e mão de obra estrangeira - elementos essenciais à continuidade do desenvolvimento econômico do Brasil que, embora fortemente baseado na agricultura, investia na incipiente indústria (REIS, 1994).

Nesse contexto, ganhou destaque no cenário nacional o engenheiro sanitarista Francisco Saturnino de Brito, que projetou e implementou trabalhos relativos ao abastecimento de água; canalização de rios; correção de impactos em corpos d'água; construção de redes de esgotos e de drenagem pluvial; aterros e dessecamento de áreas alagadiças, aplicando técnicas trazidas da Europa e outras por ele desenvolvidas. Seus trabalhos foram publicados, divulgados e aplicados tanto no Brasil quanto no exterior. Em vista da sua notória competência e do amplo panorama que sua obra proporciona - seja pela complexidade e diversidade das situações enfrentadas e pelo que esclarece sobre o alcance da ciência na interpretação da correlação entre impactos e degradação das águas -, concluiu-se ser esta importante referência no entendimento das questões relativas às águas urbanas nacionais ao final do século XIX e primeiras décadas do século $X X$, e, portanto, foi nela que a análise que segue foi centrada ${ }^{2}$.

Dentre as cidades brasileiras em que Saturnino de Brito atuou, elegeu-se para um estudo mais aprofundado o Rio de Janeiro-capital da República, referência para todas as mais prósperas cidades brasileiras da época; São Paulo, que experimentou surpreendente desenvolvimento e crescimento populacional na virada para o século XX; Recife, que sempre esteve dentre as mais importantes cidades nordestinas e brasileiras e João Pessoa, onde insere-se a bacia hidrográfica objeto de estudo da tese que originou este artigo.

A seguir, apresenta-se, de forma breve, como parte das águas doces dessas quatro cidades alcançaram o início do século XX e as contribuições do trabalho de Saturnino de Brito para o ajuste das condições 
ambientais urbanas, para a construção de uma nova paisagem e proteção de corpos d'água e recursos hídricos.

\section{A cidade do Rio de Janeiro}

Fundada em 1565, o Rio de Janeiro experimentou, a partir de 1808 (em razão do acolhimento da Corte Portuguesa), um repentino aumento populacional, que implicou em sua expansão física (RIO DE JANEIRO, 2000, p. 15-17). Os estudos de Brito (1944); Brito Filho (1971); Bulhões (1866); Costa (2006); Costa, Britto e Boucinhas (2007); Dean (1996); Fontenelle (2003); Heynemann (1995) e Prior (2008) fazem referência, direta ou indireta, a esse processo de expansão que determinou alterações significativas no relevo (desmonte de morros e aterros de extensas áreas, inclusive lagoas e trechos de baías); na hidrografia (canalização de rios, drenagem e dessecamento de áreas alagadas) e na cobertura vegetal (abate de florestas e manguezais). Tais alterações - embora tenham permitido a apropriação de mais espaço para a cidade que crescia e diversificava suas atividades produtivas e de apoio - repercutiram negativamente em alguns aspectos diretamente determinantes da qualidade do ambiente urbano: a capacidade hídrica dos mananciais que abasteciam a cidade àquela época, a dinâmica de drenagem do sítio e a qualidade da água.

Ao final do século XIX, por dispor de um sistema de esgotamento sanitário restrito (CEDAE, 2010a) e de um serviço de limpeza urbana com limitada capacidade de atuação (COMLURB, 2012), a cidade jogava às ruas, valas, fossas, canais, lagoas, praias, mangues e ao mar os resíduos que produzia: as águas servidas, o esgoto in natura, o lixo e resíduos industriais. Tais lançamentos, associados à ineficiente drenagem urbana, repercutiram negativamente sobre a salubridade e sobre as águas doces urbanas, seja pela capilaridade do solo (contaminando as águas subterrâneas) ou pelo escoamento superficial (contaminando ainda mais rios e lagoas) (BRITO, 1944, p. 1-94; MOREIRA, 1892, p. 3-8; PRIOR, 2008).

Tal contexto não condizia com a imagem pretendida para a capital da recém-proclamada República e, para adequá-la, em 1902, teve início a intervenção urbanística conhecida como reforma de Pereira Passos $^{3}$, que visou a sua infraestruturação, mo- conquistadas das águas (pelo aterro de lagoas e canalização de rios), dos mangues e do mar; e a canalização dos baixos cursos de muitos rios passou a ser uma constante na cidade. Apesar do novo visual, o Rio de Janeiro adentrou o século XX sem ter resolvido todas as questões relativas à degradação das águas doces urbanas (ou periurbanas, à época). Neste universo destaca-se o caso da Lagoa Rodrigo de Freitas que, somente em 1922, teve seu projeto de saneamento elaborado por Saturnino de Brito, pondo fim a uma questão pendente desde 1858.

Conforme Brito Filho (1971, p. 3), tal questão dizia respeito à diminuição das águas da lagoa, decorrente de intervenções realizadas nos rios que a ela afluíam, cujas águas passaram a abastecer a cidade. A diminuição considerável dessas águas afluentes causou um desequilíbrio naquele ecossistema fazendo com que as algas que penetravam na lagoa, através do canal de comunicação com o mar, não mais dispusessem de água suficiente para encobri-las e apodrecessem, comprometendo a qualidade e salubridade das águas e do ambiente no entorno. Além da decomposição das algas e da possível contaminação por esgotos, a lagoa teve sua natureza severamente alterada na ocasião em que foi convertida em lagoa de água doce e teve reduzida a sua comunicação com o mar, o que, associado à contaminação por resíduos industriais, causou o episódio da mortandade de peixes, ocorrido em 1919 (BRITO, 1944, p. 1-48; CARVALHO, 1895).

Conforme o projeto de Saturnino de Brito, em 1922, a lagoa Rodrigo de Freitas passou a ser limitada por $5.100 \mathrm{~m}$ de cais de contorno, $1.345 .800 \mathrm{~m} 2$ de margens baixas e alagadiças foram aterrados e ali foram estabelecidos logradouros públicos arborizados e pavimentados; todos os rios da bacia da lagoa foram canalizados e regularizados; dois canais com comportas, de conexão da lagoa com o mar, foram construídos; a lagoa voltou a ser salgada, como era originalmente; as redes de esgoto e drenagem foram encaminhadas para o mar e foi estabelecida a de abastecimento de água potável para o entorno então urbanizado (BRITO, 1944, p. 48). Nesta intervenção, o sanitarista aliou ao saneamento o resgate parcial do ecossistema lacustre e o "aformoseamento" do entorno através da apropriação e valorização dos atributos da paisagem natural (BRITO, 1944, p. 1-94; RIO DE JANEIRO, 2000, p. 15-18). dernização e embelezamento. Novas áreas foram

Sobre a Reforma de Pere 
Saturnino de Brito, apesar de ter atuado sob a ótica higienista (canalizações de rios e aterros de áreas alagadiças), o fez com sensibilidade singular para a época: conseguiu restaurar características importantes do ecossistema lacustre e salvaguardar importante patrimônio ambiental e paisagístico para a cidade, se antecipando em mais de sete décadas às proposições de Spirn (1995), relativas ao respeito e valorização da natureza presente no ambiente urbano.

\section{A cidade de São Paulo}

Conforme Ab'Sáber (1991, p. 9), a vila que deu origem à cidade de São Paulo, instalou-se, em 1554, num "estreito patamar de terras firmes entre dois vales afluentes da margem esquerda do rio Tietê, o Tamanduateí e o Anhangabaú" e, cresceu ocupando as colinas em redor e evitando as terras planas, mais baixas e inundáveis. No alto permaneceu por longo período, embora, em seu cotidiano, estivesse fortemente entrelaçada aos seus rios, pelo fato deles constituírem uma extensa rede de circulação através da qual, até o século XVII, se dava a comunicação com outros núcleos do litoral e do interior (REIS FILHO, 1991, p. 6). A partir dos inúmeros pequenos portos atrelados a esta rede, estruturou-se outra - as dos caminhos por terra -, que se tornaram, mais tarde, importantes vias da cidade moderna. (TOLEDO, 1991, p. 8).

Elevada à condição de cidade no início do século XVIII, São Paulo, em razão da localização que ocupava no contexto dessa rede fluvial, consolidouse como importante entreposto comercial, o que Ihe garantiu desenvolvimento no decorrer do século (OSEKI \& ESTEVAM, 2006, p. 84; TOLEDO, 1991, p. 8). A partir da década de 1730, com a chegada dos cavalos, do gado de corte e dos muares, vindos do sul, os deslocamentos por terra foram, então, incrementados, o transporte fluvial comercial foi, gradativamente, perdendo importância e o Tietê passou a atrair o "interesse social", o qual foi reforçado no século seguinte. Conta Reis Filho (1991, p. 6) que o Tietê, ainda meândrico, no início do século XIX, apesar de continuar propiciando a circulação de mercadorias e pessoas, de fornecer à cidade pescados e outros alimentos, passou a assumir outro importante papel: ser o locus do esporte (natação, remo, caçadas, futebol) e do lazer para a população (passeios pelas chácaras e clubes ali instalados), reforçando ainda mais o supracitado entrelaçamento.

Esta afeição pelos rios não impediu que continuassem sendo, também, local do descarte dos esgotos, lixo, resíduos de curtumes e matadouros e, mais tarde, das indústrias, ou que ali fossem desenvolvidas atividades poluidoras - como a lavagem de roupas Tal condição, associada ao incremento populacional, à restrita infraestrutura (abastecimento d'água, esgotamento sanitário e drenagem, principalmente) ao deficiente serviço de limpeza urbana e aos parcos recursos disponíveis para investir na qualificação do habitat urbano, findou por estabelecer a insalubridade do núcleo (ASSUNÇÃO, 2009, s/p.)

Na segunda metade do século XIX, em face da disponibilidade financeira gerada pelo êxito agrícola alcançado com a cana de açúcar e, posteriormente, com o café, a paisagem fluvial foi palco de grandes transformações: os terraços fluviais deram passagem à ferrovia (1867) (AB'SÁBER, 1991, p. 10); as indústrias e os bairros operários foram se instalando nas várzeas; muitas pontes foram reformadas e outras construídas, permitindo à cidade buscar novos espaços além dos rios, muitos dos quais conquistados pelo aterro e drenagem de áreas de várzea (ASSUNÇÃO, 2006, p. 1-9; OSEKI \& ESTEVAM, 2006, p. 84). O descompasso entre o contínuo crescimento populacional e a acanhada infraestrutura básica passou a preocupar a população e o governo. A dimensão do problema é revelada por Assunção (2009) e por Mota (2004): o sistema de abastecimento inaugurado em 1881, que atendia a 113 residências, entrou em colapso em 1888 em face do crescimento da demanda gerada pelos 5.008 edifícios então existentes. O sistema de esgotamento sanitário também foi insuficiente para fazer frente à expansão descontrolada da cidade e ao impressionante crescimento da população que aumentara quase sete vezes no período compreendido entre os anos de 1872 (31.385 habitantes) e 1900 (239.820 habitantes) (PREFEITURA DE SÃO PAULO, 2012).

Foi nesse contexto que Saturnino de Brito fo convidado a se pronunciar. No parecer emitido em 1926 fica patente a desconsideração das advertências apresentadas ao poder público em 1905 1912, 1913, 1916 e 1917, e que, de modo geral o comportamento predatório e imediatista em 
relação ao uso do patrimônio ambiental para suporte dos núcleos urbanos (em especial aquele relativo aos rios) ainda era o vigente (BRITO, 1926, p. 1). Era notório o desperdício de água, assim como dos recursos financeiros empregados na melhoria do abastecimento da cidade, uma vez que era discutível a qualidade técnica das obras realizadas - geralmente pontuais e mitigadoras -, sempre buscando a exploração de novos mananciais e nunca a correção e melhoramento do sistema instalado. O poder público não sinalizava preocupação quanto à proteção dos mananciais que abasteceriam a cidade no futuro, embora tivesse sido alertado sobre a importância da iniciativa (BRITO, 1911, p. III - 46).

Vê-se nas entrelinhas de Brito (1911, p. 14; p. 43-46), que às áreas úmidas eram direcionados os bairros destinados às populações mais pobres (menos exigentes e com menor representação política) e os usos poluentes e impactantes (cujos resíduos tinham fácil descarte nos rios); e que as águas do Tietê urbano, em meados da década de 1900, já apresentavam certo grau de comprometimento. O seu olhar sobre a gestão dos recursos hídricos refletia uma visão além da reinante àquela época (que ainda apostava na inesgotabilidade dos recursos e, por isso, os utilizava de forma pouco cuidadosa): ele anteviu o destino do Tietê. Advertiu sobre os desdobramentos de se permitir o desenvolvimento de povoações à montante e dizia que, ao condenar, naquele momento, as águas do Tietê, deixando-as poluir, se estaria conduzindo o rio ao abandono. Para ele, através da "Lei de Protecção" seria possível, desde aquele momento, conservar o rio íntegro para o futuro (BRITO, 1911, p. 46).

Oseki \& Estevam (2006, p. 84-85) relatam que a explosão demográfica das primeiras décadas do século $X X$, decorrente da substituição do café pela indústria urbana, fez a cidade de São Paulo expandir-se ainda mais, dando continuidade à ocupação das várzeas e suprimindo, paulatinamente, pelo parcelamento, "as chácaras que envolviam a área central". A pressão desta ocupação sobre os rios (representada, sobretudo, pelo lançamento de resíduos industriais e esgotos in natura e pela ocupação da várzea), determinou a exacerbação da insalubridade urbana. Em resposta à urgência da situação, novas intervenções foram realizadas, alterando significativamente a paisagem fluvial paulistana com a retificação de trechos dos rios Tamanduateí e Tietê.
Na década de 1930, grandes intervenções viárias e de engenharia hidráulica foram implementadas (LEME, 1991, p.12). Os rios foram retificados, canalizados, privados de suas várzeas, represados a pretexto do abastecimento da cidade e da geração de energia para alimentar a indústria. Isolado do convívio com a população pelo sistema viário marginal imposto pelas citadas intervenções (que acompanharam a ocorrida na Capital da República quanto à linguagem urbanística), o rio Tietê transformou-se no que Ab'Sáber, (1991, p. 9) chamou de "cloaca do mundo urbano metropolitano". Para Reis Filho (1991, p. 6), àquela época, a perda do contato com o rio não causou tanto impacto na opinião pública porque, transformado em canal de esgoto, o rio não atraia mais ninguém. Os frequentadores se retiraram e buscaram outros rios para o lazer, pois, àquele tempo eles ainda estavam disponíveis. Saturnino de Brito acertara em suas predições.

\section{A cidade do Recife}

No estuário dos rios Tejipió, Beberibe e Capibaribe estabeleceu-se o povoado do Recife. À presença destes rios com suas várzeas férteis, afirma Mayrink (2006), atribui-se o êxito do empreendimento açucareiro que despertou a cobiça e motivou a invasão holandesa em 1630. Estabelecidos no território recém-conquistado, sob o comando de Maurício de Nassau, os holandeses transformaram o Recife na cidade Maurícia e realizaram "grandiosos empreendimentos urbanísticos" (PONTUAL, 2001, p. 421-422). O apuro da técnica holandesa no domínio das águas permitiu enfrentar as dificuldades impostas pelo sítio natural à ocupação. Mayrink (2006) e Brito (1943b) relatam a realização de muitos aterros; desmate e drenagem de manguezais; construção de diques, pontes e canais; dessecamento terras baixas e úmidas; estreitamento da calha dos rios, entre outras ações.

Após a expulsão dos holandeses, a cidade continuou a expandir-se e alcançou o final do século XIX com áreas urbanizadas em redor do estuário (os bairros do Recife, Santo Antônio e São José) e na margem esquerda do Capibaribe (os bairros de Santo Amaro e Boa Vista), além de ocupações suburbanas (PONTUAL, 2001, p. 423). O Capibaribe foi o elemento estruturador do tecido urbano e indutor dessa expansão. 
Em meados do século XIX, embora tenha sido celebrado na paisagem pela intervenção urbanísticopaisagística capitaneada por Vauthier, que o envolveu em espaços públicos ribeirinhos e o adornou com muitas pontes, o Capibaribe manteve-se como local de descarte de esgoto, lixo, águas servidas e pluviais (MAYRINK, 2006, p. 135). Priorizou-se investir em melhoramentos no porto, sistema viário, transportes e comunicações e manteve-se os escravos encarregados do descarte dos excrementos e resíduos nas águas da cidade (SANTOS, 2009, p.111-113). Ao final deste século os desmatamentos na bacia, à montante do Recife, exacerbaram o poder destrutivo de suas cheias; a contaminação de suas águas decorria da contribuição da rede de drenagem de águas pluviais, do lançamento de esgotos in natura (BRITO, 1943b, p. 17-19; p. 72-77) e do vinhoto produzido nas usinas (MAYRINK, 2006, p. 137). Contaminado, o rio foi, paulatinamente, sendo esvaziado de suas funções sociais e urbanas.

Em 1909, em razão da insalubridade da cidade, Saturnino de Brito foi incumbido pelo Governo do Estado da reforma e complementação da rede de esgotos e ampliação do abastecimento de água do Recife, cujas obras iniciaram em 1910 e 1911, respectivamente (BRITO, 1943b, p. 6-7).

Conforme Brito (1943b, p. 30-36), o caos sanitário então enfrentado resultava da imundície dos espaços privados; dos defeitos da rede de esgotos e drenagem existente; do fornecimento insuficiente e da má distribuição da água; e de outro fator que colocou em destaque, considerando-o "importantíssimo": "o grande número de habitações insalubres, com compartimentos mal dispostos, sem ar e sem luz, [...] mal edificadas e mal cuidadas pelos moradores". Tollenare (1905) e Santos (2008) também se referem acerca da péssima condição sanitária e urbanística do bairro do Recife no início do século XIX.

A respeito do futuro da cidade, Brito (1943b, p. 7073) enfatizou a importância do planejamento e da infraestruturação antecederem a ocupação e de que fosse observada a topografia na abertura de novas vias, para facilitar a drenagem e o esgotamento nos novos recintos urbanos. No que concernia à paisagem fluvial urbana, aconselhou que os thalwegs fossem seguidos por vias públicas e que as margens dos rios fossem ocupadas por " pitorescas avenidas em lugar dos fundos imundos dos quintaes [...]". Referiu-se também ao lançamento das águas pluviais nos rios do estuário, colocando para o futuro a "regularização" destes "pelo cais", assim como a abertura de novos canais de concreto, ladeados por vias arborizadas, o que daria o arremate final no sistema de drenagem superficial, saneando e embelezando a cidade de então (BRITO, 1943b, p. 71-73). Fica claro, portanto, que tais recomendações se reportam ao trecho do estuário e não aos cursos destes rios, como um todo, ou a outros rios existentes no entorno da área urbanizada.

Sobre a proposição do estabelecimento de um sistema viário marginal, é plausível supor que Saturnino de Brito, profundo conhecedor da dinâmica de gestão do ambiente urbano brasileiro (mitigadora e não preventiva), pretendia trazer os rios aos olhos da cidade - estratégia que, em tese, facilitaria manter um controle mais efetivo sobre o ambiente fluvial, por parte do Estado, asseguraria a longevidade da salubridade urbana recém-adquirida e preservaria os rios da invisibilidade imposta pela posição ao fundo dos lotes e das grandes glebas urbanas então existentes. Se mantidos ocultos na paisagem, em áreas carentes de infraestrutura básica e de um serviço de limpeza urbana minimamente eficiente, os rios, fatalmente, seriam perpetuados como local de descarte do lixo e de toda a sorte de resíduos e, então, voltariam a contribuir e constituir uma ameaça à salubridade urbana.

\section{A cidade de João Pessoa}

A cidade de João Pessoa, fundada em 1585, ocupou inicialmente uma área de relevo acidentado, à margem direita do rio Sanhauá e do estuário do rio Paraíba. Segundo Lemos (2005, p.34), as peculiares condições geográficas do sítio constituíram entraves ao seu crescimento, seja pela presença do citado estuário e do manguezal que margeavam a cidade de sudoeste a nordeste; pela ocorrência da lagoa dos irerês, a leste; assim como pelos vales profundos, rios e florestas que a cercavam de leste a sudoeste.

Em meados do século XIX, a cidade pouco evoluíra espacial e qualitativamente e, em face da precariedade infraestrutural e do incremento populacional recebido (atingindo 9.000 habitantes), teve sua comprometida condição sanitária exacerbada (AGUIAR, 1993, p. 67-73; p. 111). A reforma empreendida por $B$. Roham, na década de 
1850, trouxe melhorias urbanas, mas a questão sanitária não foi resolvida em carater definitivo (OLIVEIRA, 2006, p. 69). Em 1990, após a Abolição da Escravatura e a Proclamação da República, a população mais que triplicou, fazendo a cidade expandir-se e ocupar a face oeste da lagoa dos Irerês e avançar nos arredores norte e sul (PMJP, 2005). O descompasso entre a urbanização da população e a infraestruturação determinou a poluição da referida lagoa e o incremento à insalubridade na cidade. A solução a esta questão era urgente, seja pela ameaça que constituía à população quanto pela necessidade de modernizar a cidade visando ao seu desenvolvimento.

Iniciado o século $X X$, modestamente, a capital começa a se infraestruturar e a dar melhor tratamento aos espaços públicos, no intuito de tornar a cidade mais salubre e moderna, acompanhando outras intervenções sanitaristas que aconteciam no território nacional. Nesta empreitada, provê-la de um abastecimento de água de qualidade tornou-se prioridade e, somente na segunda década do século $X X$, teve início a interveção na lagoa, em face dos lucros da exportação do algodão produzido no estado, da presença de um paraibano na Presidência da República - o Presidente Epitácio Pessoa -, e da determinação, vontade política e visão de futuro das administrações municipais das primeiras décadas do citado século, conforme Coutinho (2004, p. 42; p. 70-71).

O planejamento e realização da obra da lagoa ficou ao encargo de Saturnino de Brito que deu orientações de cunho educativo; implantou, já àquela época, o sistema "separador absoluto" na rede de coleta de esgotos e drenagem pluvial; manteve a lagoa na paisagem; refez a conexão desta com o estuário do rio Paraíba, permitindo que sua drenagem pudesse ser feita; apresentou um plano para a ocupação futura dos arredores da lagoa - o Projeto de alguns melhoramentos -, em acordo com a rede de esgotos recém-implantada; sugeriu à municipalidade a desapropriação das terras em seu entorno e, por fim, propôs o aproveitamento do potencial paisagístico do sítio através da implantação de um parque público no entorno da lagoa, que incidiria positivamente na proteção daquele corpo d'água e concorreria para o "aformoseamento" da cidade, seguindo, assim, a mesma linha de projeto adotada quando da atuação na lagoa Rodrigo de Freitas, na cidade do Rio de Janeiro (BRITO, 1943a, p. 375).

A implantação do parque Solon de Lucena, em sequência à conclusão das obras (1927), atribuiu qualidade à paisagem, desencadeou uma revolução urbanística na cidade e fez com que esta, a partir de então, passasse a assumir, nos novos espaços, a feição e a escala da modernidade. A cidade manteve-se no planalto; praticamente quadruplicou de tamanho; ultrapassou a lagoa e iniciou a ocupação da bacia do rio Jaguaribe que mantinha-se, majoritariamente, como área rural no entorno da cidade, produzindo gêneros agropecuários para o seu consumo e preservando o seu mais precioso recurso: a água doce que a abastecia (AGUIAR, 1993, p. 339; COUTINHO, 2004, p. 109-110; OLIVEIRA, 2006, p. 7; p. 165-166. ).

Em 1924, ao projetar a ampliação do abastecimento d'água, Saturnino de Brito observou que o fato da cidade ter se desenvolvido distante da maior fonte de abastecimento de água potável àquela época o rio Jaguaribe -, e de ter mantido protegido este manancial e outra importante fonte d'água - a do Tambiá -, pela presença da vegetação, assegurou o abastecimento constante, com água de excelente qualidade. No entanto, considerando o crescimento da cidade, alertou para a necessidade de se manter e desenvolver a proteção ao rio, preservando a várzea e os terrenos das encostas vertentes, estendendo-se tais cuidados à montante da mata do Buraquinho pois, caso contrário, haveria dificuldade e seria oneroso a manutenção de um abastecimento de qualidade (BRITO, 1943a, p. 350; p. 375-376; p.393).

Em 1932, a convite do Governo Estadual, o arquiteto e urbanista Nestor de Figueiredo apresentou proposta para a expansão da cidade e conexão com o distrito portuário de Cabedelo - Plano de Remodelação e Extensão da cidade de João Pessoa - que incorporava, na íntegra, a importante advertência feita por Saturnino de Brito em 1924, acerca da necessidade de se proteger o rio Jaguaribe, visando manter a integridade e qualidade do abastecimento de água da cidade. O projeto, implantado parcialmente, dentre outros atributos, preservou o rio Jaguaribe do contato direto com a cidade, em função da proteção ao abastecimento d'água, e apropriou-se da paisagem do vale para qualificar a paisagem da cidade, conforme detalha o fragmento de texto a seguir: 
Uma grande avenida-parque perimetral limitará a extensão da cidade sobre os valles do Jaguaribe e do Sanhauá, defendendo o nosso principal manancial de abastecimento d'agua potável dos perigos resultantes da approximação residencial, e conservando o bello panorama da vasta planície que dum lado da cidade se estende até Cabedello. [...]"(UNIÃO, 1932, p. 5).

Pelo exposto, vê-se que a atuação de Saturnino de Brito em João Pessoa, para a correção de questões relativas às águas urbanas, foi crucial. Sua capacidade de antever as situações e enxergar o valor potencial de cada recurso, nas suas mais amplas dimensões, contribuiu decisivamente na implantação do parque Solon de Lucena, no postergar (em mais de três décadas) do avanço da urbanização sobre o principal manancial que abastecia a cidade - o rio Jaguaribe -, e na salvaguarda da paisagem que este rio alimenta até os dias atuais, na qual se destaca a imensa mancha verde que o acompanha, onde se inserem a mata do Buraquinho (515 hectares) e os manguezais que envolvem os trechos finais do referido rio, seja no trecho desviado na década de 1920 ou na foz original.

\section{Considerações finais}

Considerando a revisão da literatura ora apresentada, observou-se que a degradação das águas doces urbanas brasileiras, inseridas no contexto da mata Atlântica, até as primeiras décadas do século $X X$ foi construída a partir de um conjunto bem diverso de fatores, dentre os quais destacam-se:

O comportamento predatório, imediatista e imprevidente no uso e exploração do patrimônio natural - em especial, as florestas e os corpos d'água -, dirigido à obtenção de riqueza ou ao imediato atendimento das necessidades e vontades humanas, com o mínimo investimento.

Esse comportamento também permeou o estabelecimento e a expansão dos assentamentos humanos. No processo de expansão urbana das quatro cidades estudadas, de modo geral, não observaram detidamente as peculiaridades e necessidades do ambiente natural, gerando impactos e problemas em graus diversos que, inegavelmente, repercutiram negativamente sobre as águas nelas contidas. As intervenções estatais empreendidas no intuito de garantir, minimamente, o funcionamento das mesmas (no que diz respeito ao abastecimento, destinação da drenagem, dos esgotos e resíduos), foram, em geral, pontuais, mitigadoras, de pouca qualidade técnica e construtiva e não observaram os problemas de forma abrangente, visando à solução definitiva. Raramente o poder público atuou preventivamente, planejando a expansão das cidades. Somente ao final do século XIX e início do século XX, quando o caos sanitário já havia se instalado nas citadas cidades, assim como em muitas outras, é que os investimentos em infraestrutura começaram a ser feitos. A postergação da infraestruturação urbana repercutiu diretamente sobre muitos corpos d'água urbanos, comprometendo a qualidade da água e o funcionamento do habitat fluvial ou lacustre e determinou o início do rompimento das relações mantidas com as cidades, relativas ao lazer e ao abastecimento (pescados e água para abastecimento).

As obras de engenharia (sanitária e viária) do final do século XIX e início do século XX reproduziram no Brasil soluções tecnicamente elaboradas, utilizadas na Europa e América do Norte. Apesar de terem melhorado significativamente a qualidade de vida em certas partes das cidades estudadas, de modo geral, não tiveram a intenção de restaurar o ambiente fluvial (ou lacustre). Muitas delas mantiveram, mascararam e até exacerbaram a degradação fluvial ao promover a remoção da vegetação ciliar, a retificação, o desvio; ao condenar muitos rios à canalização (subterrânea ou em calha aberta de concreto ou pedra), privandoos das interações com outros ecossistemas e do contato com seus espaços marginais; ao isolá-los na paisagem, encapsulando-os no sistema viário, direcionando a eles toda a drenagem urbana, dentre outras posturas.

Observa-se, contudo, que as intervenções sob o comando de Saturnino de Brito tinham uma marca incomum para a época: revelavam a sua preocupação com as questões ambientais intrínsecas a cada situação abordada; sensibilidade na percepção de elementos da paisagem que poderiam (ou deveriam) ser preservados e apropriados no processo de urbanização e saneamento de cada sítio; preocupação em informar e educar a população para as questões ambientais relativas ao ambiente urbano; o cuidado que teve em orientar o correto proceder na expansão de cada sítio tratado, através da apresentação de planos ou projetos urbanos, visando otimizar os investimento feitos e evitar que todo o esforço dedicado ao resgate da salubridade 
e da qualidade urbana fosse comprometido no futuro, pela expansão sem planejamento. Com essa postura, Saturnino de Brito aliou ao saneamento o embelezamento das cidades onde atuou e a proteção (ao menos parcial) do patrimônio natural nelas presente. Comungam desta mesma percepção sobre o trabalho de Saturnino de Brito, Lopes (2012) e Vasconcelos (2010, p. 33-34; 37-38), entre outros. A sua postura previdente contribuiu para a preservação aos dias atuais de paisagens como a da lagoa Rodrigo de Freitas, no Rio de Janeiro; a da lagoa do Parque Solon de Lucena e de parte significativa da cobertura vegetal da bacia hidrográfica do rio Jaguaribe, que permeia a trama urbana da capital paraibana.

Spirn (1995, p. 289) afirma que "o obstáculo para a construção de uma cidade melhor não é a falta de conhecimento, mas a recusa a aplicar o conhecimento". Corroborando com sua afirmação, vê-se que no Brasil, a dificuldade em aplicar e difundir o conhecimento disponível em cada época, acerca da repercussão das ações humanas sobre as águas doces também concorreu para a degradação das águas urbanas. Há registros de restrições legais vigentes no início do século XVI, que refletiam o conhecimento - embora muito limitado -, de algumas implicações decorrentes do uso indiscriminado dos recursos naturais, principalmente aquelas relativas à relação de complementaridade entre rios e florestas e às atividades cotidianas urbanas que comprometiam a qualidade das águas e do habitat fluvial. Ao final do século XIX, este conhecimento evoluíra tanto no campo da ciência quanto no da técnica e era bastante consistente. Os detalhados registros que Saturnino de Brito legou às gerações futuras demonstram que já havia conhecimento suficiente para ter impedido que muitos dos impactos às águas urbanas brasileiras continuassem a ser perpetrados. No entanto, conforme Brito (1926), se não havia muito interesse em aplicá-lo, tampouco haveria em difundi-lo junto à população. Este conhecimento, uma vez difundido e aplicado, poderia ter sido um poderoso instrumento no controle dos impactos sobre as nossas águas urbanas.

\section{Referências bibliográficas}

ABREU, Maurício de Almeida. Evolução Urbana do Rio de Janeiro. Rio de Janeiro: IPLANRIO: J. Zahar, 1987, $1^{\mathrm{a}}$. Ed.
AB'SÁBER, Aziz. Tietê: visão a galope. In: IAB/ SP (org.) Projeto Tietê. São Paulo: Pini Editora, 1991, p. 9-10.

AGUIAR, Wellington H. V. Cidade de João Pessoa: A Memória do Tempo. João Pessoa: GRAFSET, 1993, 2 ed.

ARAÚJO, Gustavo H. S.; ALMEIDA, Josimar R.; GUERRA, Antônio J. T. Gestão ambiental de áreas degradadas. Rio de Janeiro: Bertrand Brasil, 2005. p. 17-112.

ASSUNÇÃO, Paulo de. A cidade de São Paulo no século XIX: ruas e pontes em transformação. Histórica. Revista on line do Arquivo Público de São Paulo. Edição n. 10, matéria 03, maio de 2006, p. 1-9. Disponível em:<historica.arquivoestado.sp.gov.br/ materias/anteriores/edicao10/materia03/texto03. pdf $>$. Acesso em: 09 jan. 2012.

- As condições urbanas da cidade de São Paulo no século XIX. Histórica. Revista on line do Arquivo Público de São Paulo. Edição n. 37, matéria 03, s/p, agosto de 2009. Disponível em:<historica.arquivoestado.sp.gov.br/materias/anteriores/edicao37/ materia03/>. Acesso em: 09 jan. 2012.

BRANDÃO, Ambrósio Fernandes. Diálogos das grandezas do Brasil. MELLO, José Antonio Gonsalves de. (Org.). Recife: Fundação Joaquim Nabuco/ Ed. Massangana, 1997. $3^{a}$. Ed integral, p. IX - 129.

BRITO, Francisco Saturnino R. de. Abastecimento d'agua de São Paulo: Contribuição para o estudo do problema (apresentada em 1905). São Paulo: Typographia Casa Garraux, 1911.

O problema da água em São Paulo (parecer). In: Revista Technica Viação (separata). Belo Horizonte/ Rio de Janeiro/ São Paulo: P. Schneider, 1926.

Projetos e Relatórios. Saneamento da Lagoa Rodrigo de Freitas e da Baía. Rio de Janeiro: Imprensa Nacional, 1944, v. XV, p. 1-94. (Obras Completas).

Projetos e Relatórios. Saneamento de Vitória, Campinas, Petrópolis, Itaocara, Paraíba (João Pessoa), Paraíba do Sul e Juiz de Fora. Rio de Janeiro: Imprensa Nacional, 1943a, v. V, p. 284 - 430. (Obras Completas).

Projetos e Relatórios. Saneamento do Recife. Rio de Janeiro: Imprensa Nacional, 1943b, v. VIII, $1^{\circ}$. Tomo, p. 1- 382. (Obras Completas).

BRITO FILHO, Francisco Saturnino R. de. Um caso peculiar em urbanização: Saneamento de lagoa salobra poluída em clima tropical - a lagoa Rodrigo de Freitas. In: 3as Jornadas Luso-Brasileiras de Engenharia Civil(Tema Brasileiro). Luanda: Lourenço Marques, 1971, v.7, 25 p.

BULHÕES, A. M. de Oliveira. Considerações sobre o abastecimento d'aguas da cidade do Rio de Janeiro. Rio de Janeiro: Typographia Perseverança, 1866, p. $3-16$.

CARVALHO, José Luiz Sayão de Bulhões. Estado Sanitário da cidade do Rio de Janeiro em 1894. Rio de Janeiro: Imprensa Nacional, 1895, p. 1-27.

CEDAE. A história do tratamento de esgoto no Rio de Janeiro. 2010a, s/p. Disponível em:<cedae.com.br/ raiz/002002003.asp>. Acesso em: 28 dez. 2011. 
COMLURB. História da Limpeza Urbana. 2012. Disponível em:<http://comlurb.rio.rj.gov.br/emp_hist.asp>. Acesso em: 13 jan 2012

COSTA, Lúcia M. S. A. (org.). Rios e Paisagens Urbanas em cidades brasileiras. Rio de Janeiro: Viana \& Mosley; Ed. PROURB, 2006

COSTA, Lúcia M. S. A.; BRITTO, Ana Lucia; BOUCINHAS, Caio. Paisagens residuais: rios e córregos no Rio de Janeiro. In: Seminário Nacional sobre o Tratamento de Áreas de Preservação Permanente em Meio Urbano e Restrições Ambientais ao Parcelamento do Solo - APP URBANA 2007, 2007, São Paulo. Anais... São Paulo: FAU/ USP, 2007. Cd-Rom. Artigo GT3265-210-20070809200109.

COUTINHO. Marco Antônio Farias. Evolução urbana e qualidade de vida: o caso da av. Epitácio Pessoa. 2004. Dissertação (Mestrado em Desenvolvimento e Meio Ambiente) - Centro de Ciências Exatas e da Natureza/ Programa de Pós-Graduação em Desenvolvimento e Meio Ambiente/ Universidade Federal da Paraíba, João Pessoa, 2004

DEAN, Warren. A ferro e fogo: a história e a devastação da Mata Atlântica brasileira. São Paulo: Companhia das Letras, 1996

FONSECA, Alberto de Freitas Castro; PRADO FILHO, José Francisco do. Um importante episódio na história da gestão dos recursos hídricos no Brasil: O controle da Coroa Portuguesa sobre o uso das águas nas minas de ouro coloniais. Revista Brasileira de Recursos Hídricos, vol.11, n.3, jul/set 2006, p. 5-14. Disponível em:<ana.gov.br/aguaecultura/academia/docs/ Artigo\%20RBRH.pdf>. Acesso em: 01 maio 2010.

FONTENELLE, Estela Regina Hessel. Os rios urbanos e a dinâmica da paisagem: a inserção do rio Carioca na cidade do Rio de Janeiro. 2003. Dissertação (Mestrado em Urbanismo). Rio de Janeiro: FAU/ PROURB/ UFRJ, 2003

FREYRE, Gilberto. Nordeste: aspectos da influência da cana sobre a vida e a paisagem do Nordeste do Brasil. São Paulo: José Olympio, 1951, , p. 57-91.

HEYNEMANN, Cláudia B. Floresta da Tijuca: Natureza e Civilização no Rio de Janeiro - século XIX. Rio de Janeiro: Secretaria Municipal de Cultura, Departamento Geral de Documentação e Informação Cultural, Divisão de Editoração, 1995. Coleção Biblioteca Carioca, v. 38, Série publicação científica, p. 25-115.

LEME, Maria Cristina da S. No plano de avenidas nasce o Tietê. In: IAB/ SP (org.). Projeto Tietê. São Paulo: Pini Editora, 1991. p. 12-13.

LEMOS, Niedja A. B. Bacia hidrográfica urbanizada e degradação ambiental: o alto vale do rio Jaguaribe. 2005. Dissertação (Mestrado em Desenvolvimento e Meio Ambiente) - Centro de Ciências Exatas e da Natureza/ Programa de Pós-Graduação em Desenvolvimento e Meio Ambiente/ Universidade Federal da Paraíba, João Pessoa, 2005

LEWIS, Peirce F. Axioms for reading the landscape. In: MEINIG, D. W. (Org.) The interpretation of ordinary landscape. Oxford, Oxford University Press, 1979. p. 11-32.

LISTA, Antoni; SABATÉ, Joaquín (Ed. e Coord.). Projectant l'eix del Llobregat: Paisatge Cultural i Desenvolupament Regional = Designing the Llobregat Corridor:
Cultural Landscape and Regional Development Barcelona: Departament d'Urbanisme i Ordenació del Territori/ UPC, 2001

LOPES, André Luís Borges. O engenheiro Saturnino de Brito e o Urbanismo sanitarista. In: História e-história. Publicação organizada com o apoio do Grupo de Pesquisa Arqueologia Histórica da UNICAMP. 04 abril 2012. Sem paginação. Disponível em: <historiaehistoria. com.br/materia.cfm?tb=alunos\&id=435>. Acesso em: 04 ago. 2012.

MAYRINK, Vera. A formação histórica das paisagens do Rio Capibaribe na cidade do Recife. In: COSTA, Lucia M. S. A. (org.). Rios e Paisagens Urbanas. Rio de Janeiro: Viana \& Mosley; Ed. PROURB, 2006, p. 121-145.

MINISTÉRIO DO MEIO AMBIENTE. Biomas Brasileiros: Mata Atlântica. 2009. Disponível em:<mma.gov.br/sitio/ index.php?ido=conteudo. monta\&idEstrutura=72\&id Menu=3646>. Acesso em: 19 jul. 2009.

MOREIRA, M. S. Santos. Considerações sobre os meios de sanear a cidade do Rio de Janeiro. Rio de Janeiro: Typ. J. P. Hildebrandt, 1892, p. 1-9.

MOTA, Carlos Guilherme. São Paulo no Século XIX (18221889): esboço de interpretação. In: Cadernos de Pós-Graduação em Arquitetura e Urbanismo, v. 4, n. 1, p. 9-16. São Paulo: Mackenzie, 2004. Disponível em:<mackenzie.br/dhtm/seer/index.php/cpgau/article/ viewFile/136/41>. Acesso em: 04 nov.2009.

OLIVEIRA, José Luciano Agra de. Uma Contribuição aos Estudos Sobre a Relação Transportes e Crescimento Urbano: O Caso de João Pessoa - PB. 2006. Dissertação (Mestrado em Engenharia Urbana). CT/ PPGEU/ UFPB, João Pessoa, 2006.

OSEKI, Jorge H.; ESTEVAM, Adriano R. A fluvialidade em rios paulistas. In: COSTA, Lucia M. S. A. Rios e Paisagens Urbanas. Rio de Janeiro: Viana \& Mosley/ Ed. PROURB 2006. p. 77- 94.

PÁDUA, José A. Um sopro de destruição. Rio de Janeiro:

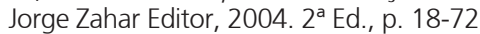

PMJP. PREFEITURA MUNICIPAL DE JOÃO PESSOA. Perfil do Município de João Pessoa (sumário). João Pessoa: PMJP, 2005.

PONTUAL, Virginia. Tempos do Recife: representações culturais e configurações urbanas. Revista Brasileira de História. São Paulo, v. 21, n42, p. 417-434. 2001. Disponível em:<scielo.br/pdf/rbh/v21n42/a08v2142. pdf>. Acesso em: 2013.

PREFEITURA DE SÃO PAULO. História demográfica do município de São Paulo. Disponível em: <http://smdu. prefeitura.sp.gov.br/historico_demografico/tabelas/ pop_brasil.php>. Acesso em: dez. 2012.

PRIOR, Tamara. Chegada da Corte: Hábitos sanitários no Brasil Colonia. In: GTÁGUAS. Revistas das águas. PGR- $4^{a}$ CCR. Ano 2, n.6, junho, 2008.s/p Disponível em:<http:// revistadasaguas.pgr.mpf.gov.br/edicoes-da-revista/ edicao-06/artigos/chegada-da-corte-habitos-sanitarios-no-brasil-colonia>. Acesso em: 28 dez 2011.

REIS, Nestor Goulart. Algumas experiências urbanísticas do início da República: 1890-1920. São Paulo: Laboratório de Produção Gráfica da FAUUSP, 1994. (Cadernos de Pesquisa do Laboratório de Estudos sobre Urbanização, Arquitetura e Preservação. Urbanização e Urbanismo, n. 01) 
REIS FILHO, Nestor Goulart. O Tietê e a cidade. In: IAB/ SP (org.). Projeto Tietê. São Paulo: Pini Editora, 1991, p. 6-7.

RIEDEL, Diaulas (org). Os canaviais e os mocambos - Paraiba, Pernambuco e Alagoas. São Paulo; Cultrix, 1959. (Coletânea Histórias e Paisagens do Brasil, vol. III, p. 20-30.

RIO DE JANEIRO (Estado). Secretaria Municipal de Meio Ambiente. Manguezais do Rio de Janeiro. Rio de Janeiro, 2000

SÁNCHEZ, Luis Henrique. Recuperação de Áreas Degradadas: Um campo multidisciplinar de pesquisas. Rio Claro: UNESP, 24 nov. 2006. (Palestra proferida). Disponível em:<rc.unesp.br/igce/pos/gma/Palestra.pdf >. Acesso em: 09 ago. 2012.

SANTOS, Manuela Arruda dos. Recife: Entre a sujeita e a falta de (com)postura. 1831-1845. Dissertação de Mestrado. Recife: Universidade Federal de Pernambuco, Departamento de Letras e Ciências Humanas. Programa de Pós-Graduação em História. Mestrado em História Social da Cultura Regional, 2009. Disponível em:<pgh.ufrpe. br/dissertacoes/MANUELA\%20ARRUDA\%20DOS\%20 SANTOS\%2OPDF.pdf>. Acesso em: 24 jan. 2012.

SPIRN, Anne. W. O Jardim de Granito: A Natureza no desenho da cidade. São Paulo: Editora da Universidade de São Paulo, 1995.
TOLEDO, Benedito Lima de. São Paulo de Piratininga: os portos de serra-acima. In: IAB/ SP (org.). Projeto Tietê. São Paulo: Pini Editora, 1991, p. 8.

TOLLENARE, L. P. de. Notas Dominicaes: Tomadas durante uma viagem em Portugal e no Brazil em 1816, 1817 e 1818. (Parte relativa a Pernambuco). Tradução de Alfredo O. De Carvalho. Prefácio de M. De Oliveira Lima. Extrahido da Revista do Instituto Archeologico e Geographico Pernambucano, n. 61. Recife: Empreza do Jornal do Recife, 1905. Disponível em: $<$ http://objdigital.bn.br/acervo digital/div obrasgerais/drg114650/drg114650.pdff >. Acesso em: 2013.

UNIÃO, A. O que será de futuro a cidade de João Pessoa. (matéria de jornal). João Pessoa: 1932, ano XLI, n. 226, 02 de out, p. 5)

VASCONCELOS, Gustavo Bruski de. Maringá Líquida: O Projeto da Cidade, as Águas Urbanas e a Ecologia da Paisagem. 2010. Dissertação de Mestrado (Programa de Pós-Graduação em Engenharia Urbana) - Departamento de Engenharia Civil/ Centro de Tecnologia/ Universidade Estadual de Maringá, Maringá, 2010. Disponível em: <peu.uem.br/Discertacoes/Gustavo.pdf>. Acesso em: 04 ago. 2012.

VIGARELLO, Georges. O limpo e o sujo. São Paulo: Martins Fontes, 1996. 